\title{
Knowledge, attitude and practice of down syndrome screening among pregnant women attending clinic in Sharjah, United Arab Emirates
}

\author{
Meena Bhati Salvi*
}

Department of Obstetrics and Gynecology, Prime Medical Centre, Sharjah attached with Prime Hospital, Dubai, UAE

Received: 07 May 2020

Accepted: 01 June 2020

\section{*Correspondence:}

Dr. Meena Bhati Salvi,

E-mail: meenabhati2007@gmail.com

Copyright: (C) the author(s), publisher and licensee Medip Academy. This is an open-access article distributed under the terms of the Creative Commons Attribution Non-Commercial License, which permits unrestricted non-commercial use, distribution, and reproduction in any medium, provided the original work is properly cited.

\begin{abstract}
Background: Down syndrome (DS) is the most common chromosomal abnormality found in live-born babies. It is associated with mental retardation, physical disabilities and growth problems. Prenatal screening to identify genetic disorders gaining importance now a days. The aim of this study was to assess the knowledge, attitude and practice among pregnant women about prenatal screening of Down syndrome.

Methods: This was a prospective study done in the department of obstetrics and gynecology in Prime Medical Centre, Sharjah. All pregnant women who attended antenatal clinic and gave the consent for the study were included. The study was conducted from April 2019 to September 2019. A self-structured questionnaire was given to these women and data was collected. Responses to pregnant women's knowledge, attitude and practice were evaluated.

Results: A total of 217 pregnant women were included in the study. Of the 217 women $64.97 \%$ had good knowledge about Down syndrome but only $23.04 \%$ women had good Knowledge regarding Down syndrome screening. Although $42.85 \%$ had right attitude towards screening but only $14.74 \%$ patients had followed good practice. Expensive test $43.65 \%$ and religious beliefs $25.39 \%$ were stated as major reasons for denial for screening tests.

Conclusions: Pregnant women have good knowledge of Down syndrome but low awareness of screening tests. Although they had positive attitude towards screening test but less patients followed good practice.
\end{abstract}

Keywords: Attitude, Down syndrome, Knowledge, Practice, Screening

\section{INTRODUCTION}

Down syndrome (Trisomy 21) is the most common chromosomal abnormality present at birth. More than 1 in 1000 new-borns is affected by Down syndrome (DS). ${ }^{1}$ The effects of DS involve a range of medical conditions in addition to cognitive impairment and intellectual disability in children and adults. ${ }^{2}$ It is associated with mental retardation (moderate to severe), physical disabilities particularly heart and growth problems. Taking into account that it is caused mainly by a meiotic accident, all pregnant women have the risk of delivering a DS baby, a risk that increases steeply with maternal age. ${ }^{3}$

As aneuploidies are major causes of perinatal death and childhood disability, screening for fetal chromosomal abnormalities should be available to all pregnant women as an essential part of antenatal care. Starting with 2007 the American College of Obstetrics and Gynecology (ACOG) recommends that screening for DS (DSS) to be available for all pregnant women regardless of age. ${ }^{4}$

Fortunately, DS can be suspected during pregnancy by combined ultrasound and serologic screening and confirmed by invasive genetic techniques. ${ }^{5}$ Invasive procedures are chorionic villous sampling ( $<13$ weeks) and amniocentesis ( $>15$ weeks) but they carry a small risk of fetal miscarriage. Recently a non-invasive test of maternal blood has become available that provides an accurate (DS detection rate of $98.6 \%$ and false-positive rate of $0.20 \%$ ) prenatal diagnosis of DS without risk to the fetus. ${ }^{6}$ This is called NIPT (non-invasive prenatal test) 
which is based on the analysis of free circulating fetal DNA in the maternal blood.

There are two options available for maternal serum screening for Down syndrome - first trimester screening and second trimester screening. In first trimester there are two methods: serum screening (double marker) and ultrasound screening (nuchal translucency). These can be used in combination (combined test). This test can be done between 11 to 14 weeks. The serum measures free beta human chorionic gonadotropin ( $\beta$-hcg) and pregnancy associated plasma protein A (PAPP-A).

If a woman books later in second trimester, the triple marker test can be taken between 14 weeks to 20 weeks. This measures free $\beta$-hcg, alpha fetoprotein (AFP) and unconjugated estriol (uE3). It is less accurate than the combined test. Once a screening test has been performed, the chance of the fetus having Down syndrome is calculated using software that takes into account maternal factors such as age, weight and family origin, along with gestation of the pregnancy.

Biochemical screening at 16-18 weeks of pregnancy can detect about $60 \%$ of pregnancies with Down's syndrome. According to NICE guidelines, the combined test has a higher detection rate and lower false positive rate when compared with other screening tests. ${ }^{7}$

Nuchal scanning alone detects $62 \%$ of all Down syndrome with a false positive rate of $5.0 \%$; combined with blood testing gives corresponding values of $73 \%$ and $4.7 \% .^{8}$

The aim of the present study was to assess the knowledge, attitude and practices of pregnant women regarding Down syndrome screening.

\section{METHODS}

This prospective study was conducted at private clinic in Prime Medical Centre, Sharjah from April 2019 to September 2019 among 217 antenatal patients. All pregnant women who gave consent for the study were included. A self-administered questionnaire was given to them. The participants were required to mark their responses against the appropriate answers on the questionnaire sheet.

The confidentiality of the participants was taken care of and data was collected. The questionnaire included demographic details of the women in terms of age, nationality, education, parity and previous abortion. A total of 21 questions were included in KAP questionnaire. Knowledge regarding Down syndrome and its screening incorporating 7 and 5 questions, regarding attitude 8 questions and 1 question regarding practice. Responses of pregnant women were evaluated on $\mathrm{Yes} / \mathrm{No}$ basis. All correct answers or all correct but one wrong answer was scored good. Thus, the percentage was calculated who had adequate knowledge and right attitude towards Down syndrome screening.

\section{RESULTS}

Total of 217 pregnant women were included in the study after taking informed consent. Characteristics of women in terms of age, nationality, education, parity and number of previous abortions were recorded.

Table 1: Socio demographic characteristics of respondents $(n=217)$.

\begin{tabular}{|ll|}
\hline Category (variables) & $\mathbf{N}=\mathbf{2 1 7}$ \\
\hline Age & $163(75.11 \%)$ \\
\hline $18-34$ years & $54(24.88 \%)$ \\
\hline $35-44$ years & \\
\hline Nationality & $88(40.55 \%)$ \\
\hline India & $38(17.51 \%)$ \\
\hline Philippines & $26(11.98 \%)$ \\
\hline Pakistan & $16(7.37 \%)$ \\
\hline Sri Lanka & $49(22.58 \%)$ \\
\hline Others & \\
\hline Education & $4(1.84 \%)$ \\
\hline$<$ High school & $61(28.11 \%)$ \\
\hline High school & $152(70.04 \%)$ \\
\hline$>$ High school & \\
\hline No. of children & $100(46.08 \%)$ \\
\hline 0 & $83(38.24 \%)$ \\
\hline 1 & $31(14.28 \%)$ \\
\hline 2 & $3(1.38 \%)$ \\
\hline 3 or $>3$ & $33(15.20 \%)$ \\
\hline Previous abortion & $184(84.79 \%)$ \\
\hline Yes & \\
\hline No & \\
\hline
\end{tabular}

(Table 1) shows the overall demographic and other studyrelated characteristics of participants. Majority of pregnant women were in age group of 18-34 years (75.11\%) with lesser no (24.88) in age group of 35-44 years. Nationality wise Indians (40.55) were more followed by Philippines $(17.51 \%)$ than other countries. Around $(70.04 \%)$ of the women were educated more than high school, (28.11\%) of females passed their high schooling and only $(1.84 \%)$ were educated less than high school. Majority of females were primigravida (46.08\%) and $(15.20 \%)$ females had previous history of abortion.

\section{Knowledge}

Most of the females who participated in the study were aware about Down syndrome but had less knowledge about its screening tests.

(Table 2) shows $93.54 \%$ pregnant women knew that Down syndrome is a genetic disease, and $80.18 \%$ knew that siblings are not always affected. $91.70 \%$ were aware about older maternal age is a risk factor and $61.29 \%$ were 
aware that routine ultrasound cannot diagnose it. According to $47 \%$ women it can be prevented and $44.70 \%$ women knew that it cannot be cured. Most of the women $(91.24 \%)$ were aware about the different types of features of Down syndrome.

Analysis of the knowledge questionnaire about screening test shows that around 59\% women knew that DS can be detected by combined test and $57.14 \%$ knew that it is done in first trimester. $24.88 \%$ were aware that combined test is better than triple marker test and $31.33 \%$ gave the correct answer that combined test is not a diagnostic test. $17.51 \%$ women knew that NIPT is not a diagnostic test (Table 3).

On analysis of knowledge about Down syndrome we found that $64.97 \%$ women had good knowledge score about DS but poor knowledge score about its screening test. Only $23.04 \%$ was having adequate knowledge about screening test (Table 4).

Table 2: Knowledge of respondents about Down syndrome $(n=217)$.

\begin{tabular}{|lll|}
\hline Questions related to Down syndrome & Correct answers & $\mathbf{n = 2 1 7 ( \% )}$ \\
\hline Is Down syndrome a genetic disease? & Yes & $203(93.54 \%)$ \\
\hline Do their siblings always have Down syndrome? & No & $174(80.18 \%)$ \\
\hline Is older maternal age a risk factor? & Yes & $199(91.70 \%)$ \\
\hline Can routine ultrasound diagnose Down syndrome? & No & $133(61.29 \%)$ \\
\hline Can Down syndrome be prevented? & Yes & $102(47 \%)$ \\
\hline Can Down syndrome be cured? & No & $97(44.70 \%)$ \\
\hline Do you know the features of Down syndrome? & (Physical features, mental impairment) & $198(91.24 \%)$ \\
\hline
\end{tabular}

Table 3: Knowledge of respondents about screening test for Down syndrome.

\begin{tabular}{|c|c|c|}
\hline Questions related to screening tests & Correct answers & $\mathrm{n}=\mathbf{2 1 7}(\%)$ \\
\hline Can DS be detected by combined test (double marker with NT scan) & Yes & $128(58.98 \%)$ \\
\hline Is combined test done in first trimester & Yes & $124(57.14 \%)$ \\
\hline $\begin{array}{l}\text { Is combined test (first trimester screening) is better than triple marker test } \\
\text { (second trimester screening) }\end{array}$ & Yes & $54(24.88 \%)$ \\
\hline Is combined test is diagnostic test & No & $68(31.33 \%)$ \\
\hline If screening test is positive then NIPT is diagnostic test & No & $38(17.51 \%)$ \\
\hline
\end{tabular}

Table 4: Overall knowledge score.

\begin{tabular}{|lll|}
\hline & Down syndrome & Down syndrome screening \\
\hline Good & $141(64.97 \%)$ & $50(23.04 \%)$ \\
\hline Poor & $76(35.02 \%)$ & $167(76.95 \%)$ \\
\hline Total & $217(100 \%)$ & $217(100 \%)$ \\
\hline
\end{tabular}

Table 5: Attitude of respondents towards screening test.

\begin{tabular}{|ll|}
\hline Attitude & Positive Attitude n=217 (\%) \\
\hline Will you undergo for screening test & $91(41.97 \%)$ \\
\hline If you have family history of Ds then will you go for screening test & $94(43.31 \%)$ \\
\hline If your previous baby is affected with DS then will you for screening test & $94(43.31 \%)$ \\
\hline If screening test is positive then will you go for NIPT & $93(42.85 \%)$ \\
\hline
\end{tabular}

\section{Attitude}

Out of 217 pregnant women who participated in the study $91(41.93 \%)$ wanted to practice DS screening, with 126 $(58.06 \%)$ not wanting to practice. When asked if family history is positive then $94(43.31 \%)$ women were willing for test, with previous history of DS baby 94 (43.31\%) women were ready for screening test. If screening test is positive then $93(42.85 \%)$ women were willing for noninvasive prenatal testing (Table 5). Overall positive attitude towards screening test was $42.85 \%$ (Table 6 ).

Out of 217 women, 126 denied for Down syndrome screening test. Majority gave the reason that it is expensive test $(43.65 \%)$. Religious beliefs were the second most common reason (25.39\%). 19.84\% was 
having fear of abnormal baby and $11.11 \%$ women was not having proper knowledge or information about the screening test (Table 7).

Table 6: Attitude Score towards Down syndrome screening.

\begin{tabular}{|lll|}
\hline Attitude score & Number & Percentage \\
\hline Good & 93 & $42.85 \%$ \\
\hline Poor & 124 & $57.14 \%$ \\
\hline Total & 217 & $100 \%$ \\
\hline
\end{tabular}

Table 7: Reasons for Denial of Down syndrome screening test.

\begin{tabular}{|ll|}
\hline Reasons for Denial & $\mathbf{N}=\mathbf{1 2 6}$ \\
\hline Lack of knowledge/information & $14(11.11 \%)$ \\
\hline Fear of having abnormal baby & $25(19.84 \%)$ \\
\hline Religious reason/beliefs & $32(25.39 \%)$ \\
\hline Expensive test & $55(43.65 \%)$ \\
\hline
\end{tabular}

\section{Practice}

Though good level of knowledge awareness about Down syndrome and positive attitude about its screening, only $32(14.74 \%)$ out of the 217 patients had followed good practice (Table 8).

Table 8: Practice of Down syndrome screening test.

\begin{tabular}{|lll|}
\hline Practice & Yes & No \\
\hline $\begin{array}{l}\text { Have you undergone for } \\
\text { screening test to detect }\end{array}$ & $32(14.74 \%)$ & $185(85.25 \%)$ \\
Down syndrome & & \\
\hline
\end{tabular}

\section{DISCUSSION}

This observational study was done to assess the knowledge of Down syndrome and its screening tests in our antenatal clinic. In our clinic we perform first trimester double marker test and in second trimester triple marker test with ultrasound for screening test. Authors also offer NIPT for high risk patients.

In this study age group of less than 35 years formed the largest with $75.11 \%$ of them belonging to this age group, this is similar to other study done by Nambiar et al. ${ }^{9}$ Though the incidence of DS is higher in elderly women (>35 years), $80 \%$ of the Down syndrome children are born to woman under 35 years age. ${ }^{9}$ Majority of women were highly educated $(70 \%)$ and this was significantly correlated to their knowledge about down syndrome and screening tests similar to another study done by Yousef et al, and Melania et al. ${ }^{10,11}$ There was no significant correlation between knowledge and different nationalities and previous history of abortions. There was no association between the knowledge and other demographics like parity and age of participants similar to other studies. ${ }^{10,12}$
This study found that women have good knowledge about Down syndrome. Most of them knew it is a genetic disease which is related to previous study findings. ${ }^{13,14}$ $80 \%$ participants believed that siblings are not always affected similar to other study done by Mohammed et al. ${ }^{14}$ Older maternal age was most frequently mentioned as a maternal risk factor for DS, and many participants (92\%) gave the correct answer which is similar to other study done by Denise et al. ${ }^{6} 61.29 \%$ participants believed that DS cannot be diagnosed by routine ultrasound. $47 \%$ gave the correct answer that DS can be prevented and $44.70 \%$ believed that DS cannot be cured. This finding is similar to other study. ${ }^{14}$ Majority of participants $(91.24 \%)$ were aware about the features of Down syndrome which is similar to study done by Denise et al. ${ }^{6}$ In this study overall knowledge score was $65 \%$ which is more comparative to another study done by Yousef et al $(19.71 \%) .^{10}$

Antenatal screening for DS is now a well-established practice in many countries. Recently, the focus of antenatal screening of DS has been on the first trimester of pregnancy. In this study about $59 \%$ of pregnant women knew that DS can be detected by combined tests and $57 \%$ knew that it is done in first trimester but only $25 \%$ were aware that it is better than second trimester triple test screening and $31 \%$ stated that it is not a diagnostic test. $17.51 \%$ of the women stated that NIPT is not a diagnostic test. NIPT is a new test so it may be a reason that many of the patients were not aware of the test.

In this study all participants reported having some knowledge about the screening tests but when we assessed overall knowledge score, only few participants had detailed knowledge of this. Overall knowledge score of screening tests was $21.04 \%$. This study results related to participants knowledge about screening tests support previous study findings. Nambiar et al, found that $11.5 \%$ had good knowledge about screening tests 9 and Baxi A et al, found that $14.2 \%$ were aware about screening tests. ${ }^{15}$ In study done by Emre et al, awareness about the first and second trimester PST [nuchal translucency (NT), triple test] was $21.6 \%$ and $59.7 \%$ respectively. ${ }^{16}$ Majority of the patients in our study were aware about the disease but not about the measures to screen it. Thus, indicating health care providers can play a major role to educate women about screening of Down syndrome.

In the present study participants having higher knowledge level were associated with positive attitude. About $42 \%$ agreed to undergo screening tests. $41.37 \%$ participants would agree for screening tests with previous family history or previous baby affected with Down syndrome while in study done by Nambiar et al. ${ }^{9}$ It was $83.3 \%$ and $84.6 \%$ respectively. $43 \%$ showed interest in doing NIPT if screening test would become positive. Thus overall, ninety-three $(42.85 \%)$ out of 217 participants showed positive attitude score. 
This finding is similar to other findings which showed positive attitudes. Most responders agreed to undergo first trimester $(84 \%)$ or second trimester $(80 \%)$ screening in a future pregnancy in study done by Amina et al. ${ }^{17}$ Most pregnant women $(77.6 \%)$ had a positive attitude to Down syndrome screening in study done by Pruksanusak et al. ${ }^{18} 78.9 \%$ and $64.7 \%$ had a positive attitude for screening tests in study done by Melania et al, and Nambiar et al, respectively..$^{9,11}$

Although $42.85 \%$ of the women were interested in DS screening and $23.04 \%$ were having good knowledge, only $14.75 \%$ had gone for screening tests. This is comparable to other studies. In study done by Emre et al, awareness about the first and second trimester screening was $21.6 \%$ and $59.7 \%$, whereas use of them was $13.7 \%$ and $44.8 \%$, respectively. ${ }^{16}$ Nambiar et al, found that $64.7 \%$ of the women had right attitude towards screening tests and $46.1 \%$ patients had undergone the test. ${ }^{9}$

Out of 217 pregnant women, 126 denied for Down syndrome screening test. Majority gave the reason that it is expensive test $(43.65 \%)$. Religious beliefs were the second most common reason $(25.39 \%) .19 .84 \%$ was having fear of abnormal baby and $11.11 \%$ women was not having proper knowledge or information about the screening test. This finding suggest that emphasis should be given to proper counselling and education during antenatal visits to each patient so that they can understand the Down syndrome and its screening without fear. Healthcare provider can play a major role to increase the right attitude and good practice.

The limitations of this study are that it was conducted at one clinic involving a limited number of pregnant women. Therefore, the findings cannot be generalized but this give an idea about knowledge, screening and practice and how we can improve the practice by increasing the awareness of existing screening tests in our clinic.

\section{CONCLUSION}

Despite high knowledge about Down syndrome and positive attitude practices among pregnant women towards Down syndrome screening were less. Its cost, religious beliefs, fear and less knowledge appear to be limiting factors for its poor acceptability. Proper, information, education and counselling should be implemented in early ante natal visits to increase the awareness.

\section{Funding: No funding sources}

Conflict of interest: None declared

Ethical approval: Not required

\section{REFERENCES}

1. Patterson D. Molecular genetic analysis of Down syndrome. Human Genetics. 2009;126(1):195-214.
2. Geelhoed EA, Bebbington A, Bower C, Deshpande A, Leonard H. Direct health care costs of children and adolescents with Down syndrome. J Paediatr. 2011;159(4):1-12.

3. Palomaki GE, Lee JE, Canick JA, McDowell GA, Donnenfeld AE. Technical standards and guidelines: prenatal screening for Down syndrome that includes first-trimester biochemistry and/or ultrasound measurements. Genet Med. 2009;11(9):669-81.

4. Wilson KL, Czerwinski JL, Hoskovec JM, Noblin SJ, Sullivan CM, Harbison A, et al. NSGC practice guideline: prenatal screening and diagnostic testing options for chromosome aneuploidy. J Genet Couns. 2013;22:4-15.

5. American Congress of Obstetricians and Gynecologists (ACOG). ACOG' screening guidelines on chromosomal abnormalities, 2007. Retrieved 11-06-2012. Avaliable at: http://www.acog.org/About_ACOG/News_Room/Ne ws_Releases/2007/ACOGs_Screening

Guidelines_on_Chromosomal_Abnormalities. Accessed on $12^{\text {th }}$ March 2020.

6. Levis DM, Harris S, Whitehead N, Moultrie R, Duwe K, Rasmussen SA. Women's knowledge, attitudes, and beliefs about down syndrome: a qualitative research study. Am J Med Genet A. 2012;6:1355-62.

7. Chasen ST, Perni SC, Kalish RB, Chervenak FA. First-trimester risk assessment for trisomies 21 and 18 in twin pregnancy. Am J Obstet Gynecol. 2007;197(4):374.e1-3.

8. Muller F, Benattar C, Audibert F, Roussel N, Dreux $\mathrm{S}$, Cuckle H. First-trimester screening for Down syndrome in France combining fetal nuchal translucency measurement and biochemical markers. Prenat Diagn. 2003;23(10):833-6.

9. Nambiar MK, Roopa PS, Nisha C, Kumar P. Downs syndrome and its screening: how aware are we? Int $\mathbf{J}$ Reprod Contracept Obstet Gynecol. 2018;7:1186-90.

10. Binjahlan YE, Mahmood M, Binjahlan MM, Alqurashi AG, Alqurashi GG, Zirari MA, et al. Assessment of knowledge, attitude and practice toward down syndrome in Jeddah City, Saudi Arabia 2016. The Egypt J Hospital Med. 2017;66(1):146-51.

11. Pop-Tudose ME, Popescu-Spineni D, Armean P, Pop IV. Attitude, knowledge and informed choice towards prenatal screening for Down Syndrome: a cross-sectional study. BMC Pregn Childbirth. 2018;18(1):1-8.

12. Gidiri M, Holding S, Lindow SW. Reduction in Down's syndrome screening acceptance is predominantly observed in women aged 25-35 years. Womens Health (Lond Engl). 2010;6(4):525-9.

13. Gilmore L, Campbell J, Cuskelly M. Developmental expectations, personality stereotypes, and attitudes towards inclusive education: community and teacher views of Down syndrome. Int J Disabil Dev Educ. 2003;50:65-76.

14. Alhaddad MH, Anwer F, Basonbul RA, Butt NS, Noor MI, Malik AA. Knowledge and attitude 
towards Down syndrome among people in Jeddah, Saudi Arabia. Proceedings SZPGMI Vol. 2018;32(1):56-65.

15. Baxi A, Kaushal M. Awareness and acceptability in Indian women of triple test screening for Down's syndrome. Internet J Gynecol Obstet. 2007;9(2):16.

16. Yanikkerem E, Ay S, Çiftçi AY, Ustgorul S, Goker A. A survey of the awareness, use and attitudes of women towards D own syndrome screening. J Clin Nurs. 2013;22(11-12):1748-58.

17. Belahcen A, Taloubi M, Chala S, Izgua AT, Alaoui AM. Mother's awareness and attitudes towards prenatal screening for Down syndrome in Muslim Moroccans. Prenatal Diagnos. 2014;34:821-30.
18. Pruksanusak N, Suwanrath C, Kor-Anantakul O, Prasartwanakit V, Leetanaporn R, Suntharasaj T, et al. A survey of the knowledge and attitudes of pregnant Thai women towards Down syndrome screening. J Obstet Gynaecol Res. 2009;35(5):87681.

Cite this article as: Salvi MB. Knowledge, attitude and practice of down syndrome screening among pregnant women attending clinic in Sharjah, United Arab Emirates. Int J Reprod Contracept Obstet Gynecol 2020;9:2765-70. 